\title{
DIFFICULTIES IN POST-TSUNAMI RECONSTRUCTION PLAN FOLLOWING JAPAN'S 3.11 MEGA DISASTER:DILEMMA BETWEEN PROTECTION AND SUSTAINABILITY
}

\author{
Katsuya HIRANO 1 \\ ${ }^{1}$ Member of JSCE, Associate Professor, Disaster Information Management and Public Collaboration Division, \\ International Research Institute of Disaster Science, Tohoku University \\ (Aoba 6-3-09, Aramaki, Aoba, Sendai 980-8579, Japan) \\ E-mail: hirano@plan.civil.tohoku.ac.jp
}

\begin{abstract}
After the 11 March 2011 tsunami, post-tsunami reconstruction planning has started. In this article several key points and difficulties in the reconstruction plan are introduced based on the experiences of the author, who is part of the planning process. Before explaining the problems with the reconstruction plan, comprehensive planning problems in rural areas are introduced. These problems are population decline, a super-aging society, decline of city/town centre and land problems. Next, the goal of post-tsunami reconstruction is argued through the key concept of "building back better" to confirm the purpose of the reconstruction. Finally, based on the tsunami protection level and its background thought, a number of dilemmas are discussed. For example, the result of the reconstruction project of "moving to higher ground" means a separated city/town/village, yet a compact city/town/village concept is required in the population decline phase.
\end{abstract}

Key Words : post-tsunami reconstruction plan, moving to higher ground, planning of coastal levee

\section{INTRODUCTION}

On 11 March 2011, a huge tsunami devastated almost all coastal cities, towns and villages on the east coast of the Tohoku region in Japan. Based on the "White Paper on Disaster Management 2011", the outcome of the damage was a total inundated area of over $560 \mathrm{~km}^{2}$, over 23,000 dead or missing, and over 160,000 houses and buildings destroyed.

Faced with the crisis, the Japan Society of Civil Engineers (JSCE) promoted several research and investigation projects. The achievements of these projects were introduced in "One Year after the 2011 Great East Japan Earthquake - International Symposium on Engineering Lessons Learned from the 2011 Great East Japan Earthquake". The symposium was organized with collaboration between JSCE and five academic societies related to engineering in Japan. The damage and its mechanisms were well investigated and reported at the symposium.

On the other hand, in terms of reconstruction planning, there are few reports and investigations. This would be related to the fact that all specialists who are involved in reconstruction of tsunami-affected areas are concentrating on examining actual reconstruction planning and consensus building. Currently, almost all tsunami-affected areas are moving from making a conceptual whole city/town plan to designing concrete, individual project design steps. This aspect of reconstruction planning is faced with several difficulties and dilemmas. The issues should be shared with international societies.

The author has taken part in reconstruction planning for the city of Ishinomaki and the town of Minamisanriku, both in Miyagi Prefecture, and in a visual quality assessment of the new coastal embankment of Miyagi and Iwate prefectures, as an expert in urban design and architecture for infrastructure.

Drawing from the author's experience at Ishinomaki and Minamisanriku, his visual assessment of the embankments and discussions with many colleagues, the principles of reconstruction planning and its difficulties are introduced in this article. In Fig. 1, the names of places that are referred to in this article and their geographical locations are shown for foreign readers. 


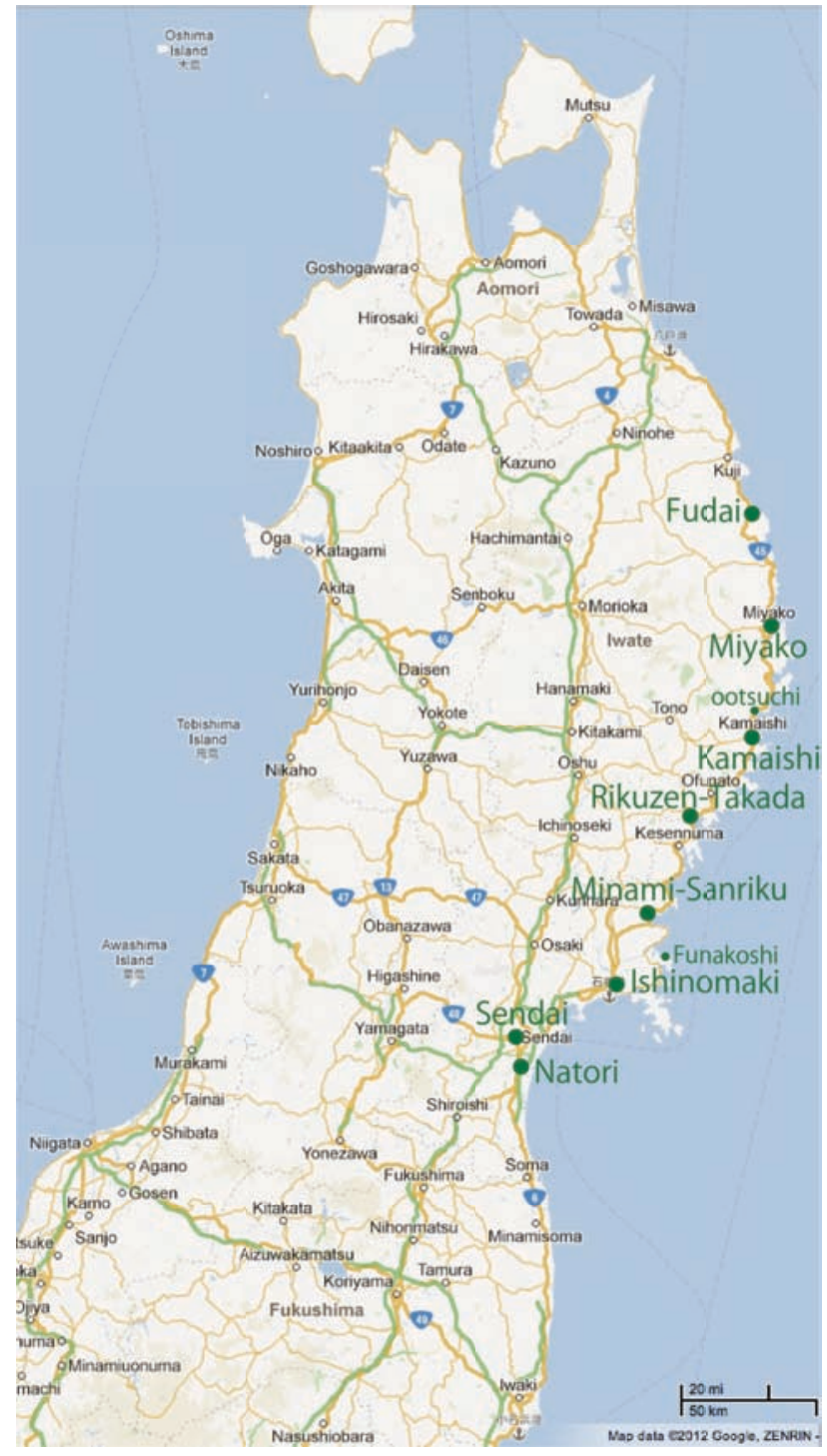

Fig. 1 Map of Tohoku region with places referred to in this article. (copyright 2012, Google, ZENRIN. Place names added by Author.)

\section{COMPREHENSIVE PLANNING ISSUES IN RURAL AREAS IN JAPAN}

Before considering post-tsunami reconstruction planning, three comprehensive issues in city/town planning in Japanese rural areas are explained in this section. These problems should be addressed because they have a prerequisite role in reconstruction planning.

\section{(1) Population decline and a super-aging society}

The first issue is population decline and a super aging society. According to Japan's National Institute of Population and Social Security Research, the total population of Japan is decreasing. Based on the latest population projection for $2012^{2)}$, the total population of Japan will decrease from 128 million in 2010 to 87 million in 2060. In addition, the ratio of high-aged people, taken as over 65 years old, will increase from $23 \%$ in 2010 to $40 \%$ in 2060.

These severe tendencies are more drastic in rural areas. This fact means that almost all inundated areas had been suffering this severe problem of population decline and super-aging even before the tsunami disaster. For example, the General Town Planning of Minamisanriku $2007^{3)}$ supposed that the future population of Minamisanriku would decrease from 20,000 in 2005 to 17,000 in 2016, and the ratio of those with a high age would increase from $28 \%$ in 2005 to $35 \%$ in 2016. Compared with the national population projection, the severity of the town's projection was easily understood.

After the tsunami, around 800 people from the town were dead or missing, and around 1,300 people moved out of the town. Thus, it is possible to say that the tsunami disaster accelerated this population problem.

\section{(2) Decline of city/town centre}

The second issue is the decline of the city/town centre. This might be a common problem in motorized countries. Japanese regulations to control big retail parks are comparatively loose. So, the situation seems more severe than for European city/town centres.

In rural areas, a low population density means a low service level of public transport, a low service level of public transport means high vehicle ownership rates, and a high vehicle ownership rate causes the service level go even lower. As a result of this vicious circle, nearly every adult person has one vehicle in rural areas in Japan. Needless to say, this vicious circle drives retail parks in the suburbs to prosperity, while on the other hand, the city/town centre declines.

Ishinomaki has a population of 152,000 . This may be considered large, but no one could stop the decline of the city centre even before the tsunami disaster. According to the "Central City Area Activation Basic Plan of Ishinomaki 2009", ") which was planned to counter the decline, in terms of sales amount, the share of the city centre decreased from $14 \%$ in 1994 to $8 \%$ in 2007. In terms of retail space, total retail space of the whole city of Ishinomaki is increasing from around 200,000 $\mathrm{m}^{2}$ in 1994 to $300,000 \mathrm{~m}^{2}$ in 2007 , but the retail space in the city centre decreased from $36,000 \mathrm{~m}^{2}$ in 1994 to 31,000 $\mathrm{m}^{2}$ in 2007.

As a result of decline, "shutter street" was born as a new term in Japan. It means that closed shops (shuttered shops) can be found in rows on the street. Almost all cities and towns in rural areas in Japan have several shutter streets in the city centre. 
Unfortunately, almost all city/town centres in the tsunami-affected areas are located by the coast, because they are port towns. Therefore, almost all the city/town centres suffered huge damage. On the other hand, several retail parks in the suburbs were not damaged. Of course, tsunami-affected areas are not so urban as to have a big retail park, but several large cities, such as Ishinomaki, Kamaishi and Miyako, have a big retail park in their suburbs.

From the aspect of the decline of the city/town centre, the tsunami disaster also accelerated this problem to a more severe situation. Centre area revitalization is a very important topic in rural cities, the same as in other motorized countries.

\section{(3) Land problems}

The last issue is land problems. The first is real property registration matter; the second is real estate transactions matter.

\section{a) Real property registration problem}

Accurate cadastral maps cover only half the area of Japan. Old cadastral maps, which are just like a sketch map, still remain in rural areas. Moreover, a large number of lands have never undergone the inheritance procedure in rural areas. These situations cause difficulties in land transactions. The former case is directly connected to boundary troubles. For the latter case, buyers need to find a legitimate heir and let him/her follow the inheritance procedure before a contract is made or else undergo a troublesome legal procedure.

In a typical case, these points do not become a huge problem, because development projects are few in rural areas. However, in reconstruction planning, these points become a difficult problem. Consider an actual case at some fisherman's village in Ishinomaki, for example. A site was selected as the most suitable for "moving to higher ground". In fact, that site is a common property of the fisherman's village. Thirty co-owners are recorded at the register, but six of the co-owners were never updated from two generations ago. It is quite difficult to find six present legitimate heirs and it would take a long time to go through a legal procedure without legitimate heirs. As a result, this site was abandoned as one of the alternatives, in spite of its having the most suitable location.

\section{b) Real estate transaction problem}

As a population grows, the land area of Densely Inhabited Districts (DIDs) becomes larger and larger. In this phase of a society, population density does not decrease with appropriate development control. However, in the decline phase, it is difficult to reduce the land area of DIDs, because there are many old residents even in the fringes of the DID. Thus, it is difficult to maintain population density,
Table 1 Changes in the Densely Inhabited District (DID) population and population density in Ishinomaki ${ }^{5)}$

\begin{tabular}{ccccc}
\hline & Rate & $\begin{array}{c}\text { Land } \\
\text { of } \\
\text { Change } \\
(\%)\end{array}$ & $\begin{array}{c}\text { Area of } \\
\text { DID } \\
\left(\mathrm{km}^{2}\right)\end{array}$ & $\begin{array}{c}\text { Population } \\
\text { Density in } \\
\text { DID } \\
\left(\text { person } / \mathrm{km}^{2}\right)\end{array}$ \\
\hline 1980 & 93,094 & - & 18.9 & $4,925.6$ \\
1985 & 94,962 & 2.0 & 19.9 & $4,772.0$ \\
\hline 1990 & 96,511 & 1.6 & 21.1 & $4,574.0$ \\
\hline 1995 & 103,518 & 7.3 & 23.4 & $4,423.8$ \\
\hline 2000 & 101,723 & -1.7 & 25.9 & $3,927.5$ \\
\hline 2005 & 97,637 & -4.0 & 25.9 & $3,769.8$ \\
\hline
\end{tabular}

and population density will be forced to decrease in the decline phase. A low population density will lose efficiency at the management cost of the city. Thus, the real estate transaction problem will be much severer in the decline phase in Japan.

Moreover, a curious phenomenon occurs in the decline phase in rural areas in Japan. Table 1 shows the changes in the DID population and land area in Ishinomaki. As the DID population grew until 1995, the land area of DIDs also increased. However, after 1995, the land area of DIDs still increased in spite of the decline phase of the DID population. This inconsistency is not a mistake in the growth control program of Ishinomaki City Planning.

Needless to mention, demographic change is determined by a balance of natural and social change. This means that there is a definite number of persons who move in even in the decline phase. Also, there is a definite demand for land in order to move from a flat to a detached house within the city.

However, supply for that demand is not sufficient in the rural area, in spite of many vacant lands within the DID. As a result of shortage of supply, new developments are needed even in the decline phase. The floor market and rent market are also almost the same as the land market. Many deserted houses and vacant shops in DIDs are neither for sale nor for rent. This curious phenomenon is common within the rural cities of Japan.

The factors in this supply shortage include difficult and complex problems, such as the tax system, related law, historical changes in taxes and laws, market conditions, and social psychological thinking of the Japanese people. To solve the land problem is not the purpose of this article, so investigation of this problem is given to appropriate scholars.

Landowners do not have a high incentive to use land in rural areas in Japan. This is a fact that a large number of rural cities face. It will be too difficult to manage city planning in the decline phase without activation of real estate transactions. Tsunami-affected areas are not exceptions to this problem. 


\section{(4) Comprehensive direction of city/town/village in rural areas of Japan}

The original concept of a compact city/town /village was examined from aspects of environmental sustainability, such as energy consumption. However, it has extended to a wider concept, which includes economic and social aspects, such as economic viability, maintenance cost of lifelines and community activity. Just recently, no city planner had doubts about the compact city as the right way for future cities or towns.

In the case of population decline and a super-aging society, the compact city/town/village becomes not a preferable direction but a minimum requirement, because sustainability for municipal finance, public transport, community activity and so on is a more critical problem. Therefore, the compact city should be materializing in the rural areas in Japan. It is possible to say that this is a common thought between city planners in Japan. The Well-Shrinking City/Town is needed for rural areas of Japan.

To materialize a compact city in Japan, some breakthrough is needed against the land problem. The "Fixed Term Land Lease Right" seems to be one of the most important solutions. The Japanese Act on Land and Building Leases was revised to activate real estate transactions and to reduce vacant lands in 1991. In this revision, the provision of "Fixed Term Land Lease Right" was added. According to this provision, landowners can easily lease their land with stronger ownership than the ordinary land lease before.

Using this provision, several challenges have already been met. One of the most famous projects is the Marugame-machi shopping street, in Takamatsu, Kagawa Prefecture. Using the provision, this shopping street succeeded in separating land use and land ownership with appropriate area management and also succeeded in revitalizing the shopping street in the city centre.

\section{GOAL OF THE RECONSTRUCTION}

In the previous section, general problems and the importance of a compact city/town/village in rural areas in Japan were shown. Before proceeding to specific problems in post-tsunami reconstruction planning, in this section, the goal of the reconstruction is considered to make the author's point clear.

\section{(1) Ambiguity of the goal}

"Building Back Better"-this is a beautiful phrase, used for post-disaster recovery and reconstruction. The United Nations often uses this catch- phrase for post-disaster assistance activities, for example. A similar key word is used in Japanese. It is "fukkou" in contrast to "fukkyu". The meaning of "fukkyu" is almost the same as "recovery" and to building something back to be the same as before. On the other hand, "fukkou" means just the same as "building back better" and something more than "fukkyu". Many media and municipal government units have stated "not a 'fukkyu' but a 'fukkou".

What is "better"? An ambiguity of this tagline has already been pointed out by Kennedy et al. (2008). ${ }^{6}$ They said that "better" has multiple interpretations, many of which have caused further problems. Based on post-tsunami fieldwork in Aceh, Indonesia and in Sri Lanka, which were hit by tsunami in 2004, they concluded that "building back safer" is preferable in the case of Aceh and Sri Lanka. A similar problem has occurred after the tsunami in Japan. The meaning of "fukkou" should be examined, because the word "fukkou" is also ambiguous.

\section{(2) Goal of reconstruction in decline phase}

In the old days, the meaning of "fukkou" from former large disasters was certainly economic and demographic growth, because the whole of Japan was still in the growth phase. After the collapse of the economic bubble, the Japanese economy moved into a low growth phase in the early 1990s, and the peak of the total population of Japan was at the end of the 2000s. Therefore, this is Japan's first experience in post-disaster reconstruction with just low economic growth and a demographic decline phase. Perhaps, this may be a first experience for the world. Therefore, according to some kind of law of inertia, there are quite a few persons who consider "fukkou" and "better" to include economic growth even in this decline phase. Some kind of law of inertia also exists in the planning sense, and some planners stick to thoughts of a growth period such that higher buildings become good property of a city.

After the collapse of the economic bubble in Japan, Japanese city/town planning was changed gradually. The government's expenditure for public works was reduced from 14.9 trillion yen in 1998 to 6.2 trillion yen in $2011^{7)}$. Under this financial environment for public works, city planning shifted from urban to community development, in other words, from big projects by the public sector and large enterprises to small projects by the public sector, nonprofit organizations and residents. This kind of new movement of community development is called "machi dukuri" in Japanese.

From an overview of recent community development in Japan, it seems that projects that succeeded have two common features. The first is that 
the project's aim is to improve the residential environment for residents, except in some villages with hot springs. The second feature is a high quality of design with public participation and residents' initiative.

In other words, it is possible to say that the purpose of successful community development is place attachment and pride in the hometown, instead of economic or demographic growth.

The goal of post-tsunami reconstruction should follow this new thought on community development. Thus, the meanings of "fukkou" or "better" might be stronger place attachment and pride in the hometown even in post-tsunami reconstruction.

Of course, before considering such a goal, the concept of "building back safer" should be considered. In the next section a new tsunami protection level in Japan is introduced as a basis of reconstruction planning.

\section{TSUNAMI PROTECTION LEVEL}

Strong concrete structures were destroyed easily by the tsunami (Fig. 2). It was powerful enough to make civil engineers hesitate to provide protection against a huge tsunami through the use of facilities. No one is able to resist the great forces of nature. In fact, it was heard that there were some cases in which residents relied on the embankment and lost their lives because they did not evacuate.

On the other hand, in the village of Fudai, Iwate Prefecture, an embankment $15 \mathrm{~m}$ in height completely protected the village against even the tsuna$\mathrm{mi}$ in 2011. This event is called the "Miracle of Fudai".

To decide on a tsunami protection level is a difficult and irresolute issue. In another words, "to protect or not to protect, that is the question".

\section{(1) The new standard for tsunami prevention}

The Central Disaster Prevention Council (CDPC) of Japan is an organization which was founded based on the Disaster Countermeasures Basic Act and organized under the Cabinet. The chairperson of the CDPC is the prime minister, and members include all ministers, heads of major public institutions and experts. The CDPC decides crucial policies for disaster prevention in Japan. On 27 April 2011, the CDPC created a new committee to decide new countermeasures, based on the experience from the 2011 earthquake off the Pacific coast of Tohoku. The name of the committee is a little long: Committee for Technical Investigation on Countermeasures for Earthquakes and Tsunamis Based on the Lessons

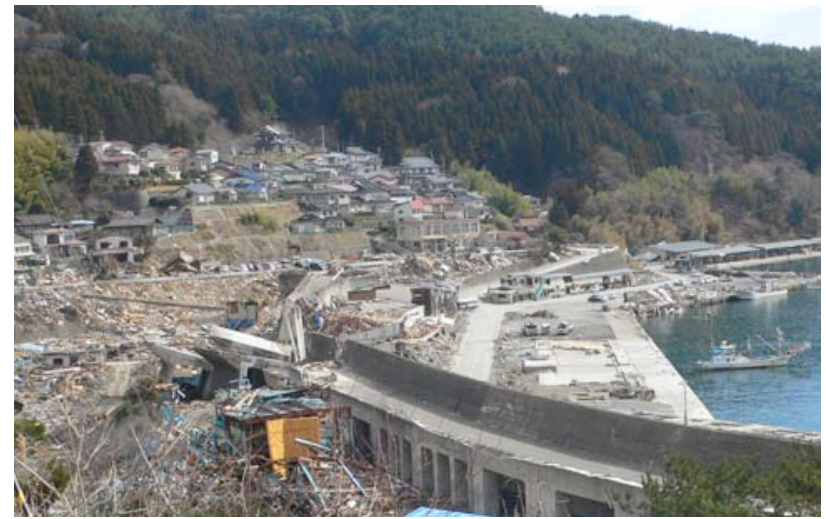

Fig. 2 Destroyed concrete levee in Koshirahama, Kamaishi, Iwate Prefecture. Height of levee was $11.8 \mathrm{~m}$.

Learned from the "2011 off the Pacific coast of Tohoku Earthquake" (CTICET). CTICET discussed broad topics related to earthquakes and tsunamis, including a new standard for the tsunami protection level.

The new standard was decided on 26 June 2011 in the interim report of CTICET ${ }^{8)}$. Of course, the interim report was not official or a final decision, but it was treated as a virtual decision for speedy reconstruction. It took over three months to decide on a new standard. It is easy to criticize that it took so long, but it seems that this decision making included difficult judgments, because the new standard covers not only reconstruction planning on the tsunami-affected areas but also whole tsunami supposed coasts in Japan. Whole tsunami supposed coasts mean nearly equal to the whole coast of Japan. Thus, CTICET should carefully consider not only safety but also the cost of coastal facilities, effect on environment or landscape, usability of daily life and so on.

\section{(2) Two levels of tsunamis}

Finally, CTICET set an assumption of two levels of tsunamis as the new standard. The first level is the "frequently occurring tsunami", called "Tsunami Level One (L1)". The frequency of occurrence of L1 is supposed to be once per several decades to 150 years. Against L1, a principle for countermeasures is to use coastal protection facilities, such as a coastal levee.

The second level is the "largest-possible tsunamis", called "Tsunami Level Two (L2)". L2 is supposed to be larger than L1. The frequency of occurrence of L2 is supposed to be once every 500 years or longer. Against L2, a principle for countermeasures is not protection but evacuation of local residents. The tsunami on 11 March 2011 is included under L2.

In terms of the difference of L1 and L2, for example, at Minami-Sanriku, Miyagi Prefecture, the 
tsunami height (i.e., L2) was over $20 \mathrm{~m}$, and the designed height of the L1 levee was $8.7 \mathrm{~m}$. On the other hand, At Ootsuchi, Iwate Prefecture, L1 (14.5 $\mathrm{m})$ is almost the same as L2 $(15.1 \mathrm{~m})$. In fact, the heights of L1 and L2 are diffrent from bay to bay, but the southern part of the ria coast has a large difference between L1 and L2. Moreover, the L1 height in the plains area of Miyagi Prefecture is lower than its designed high tide, thus the height of the coastal levee is decided not by a tsunami but by high tide.

According to paleo-tsunami researches on the same area, geomorphologic evidence on the Jogan tsunami in AD 869 shows a similar scale to the 2011 tsunami. Sugawara et al. (2012) ${ }^{9)}$ discussed the similarities and differences between the 2011 and 869 tsunamis. Moreover, the Keicho tsunami in 1611 seems to have been on a similar scale, but in the Sendai Plain, no evidence of this has been found yet. The achievement of the paleo-tsunami researches is that they show the frequency of L2 in the Pacific coast of the Tohoku region to be at least one per over 400 years.

The assumption of a protection level and damage reduction level is a recent mainstream in the countermeasures for disaster in Japan. For example, the Japanese design standard for bridges also has this kind of assumption, which is earthquake levels one and two. Against earthquake level one, bridges should not break, while against earthquake level two, bridges should avoid fatal collapse. It is possible to say that the new standard for tsunami countermeasures follows this recent mainstream of countermeasures for other disasters. The frequency of L2 is quite rare enough to be beyond the period of durability of a protection facility. Considering the time scale of L2 and the durability, this assumption is rational in terms of the engineering aspect.

Moreover, the protection level for major Japanese rivers is planned from 30-years flood to 200-years flood, in fact. Frequency and probability are different concepts in mathematics, but, to protect at L1 has clear correspondence to river flood protection level in Japan. Equity also should be a concern in disaster prevention, therefore, it is possible to say that the new standard is rational in this aspect.

Finally, the national government decided to construct a coastal levee for L1 in the whole area inundated by the tsunami of 2011 .

\section{(3) Once per 500 years vs. actual experience}

As mentioned in the last sub-section, the decision for the new standard is a rational judgment. The occurrence of tsunami once per 500 years is historical fact. However, even if historians or scientists insist that it occurs once every 500 years, for the survivors it was simply a tsunami that they actually experienced. This difference in sense of time is quite critical and essential for reconstruction planning.

Needless to say, when promoting reconstruction in a devastated city/town/village, it is indispensable that tsunami survivors feel safe. According to the new standard, the countermeasure for L2 will not protect them. It was quite difficult to build a consensus without protection against the actually experienced tsunami level. Faced with this gap in sense of time, municipal governments sought damage-reduction solutions against L2 within the new standard.

As a result, three major solutions were introduced in the reconstruction plan of municipal governments. The three solutions are "Principle of moving to higher ground", "Principle of Multi-layer Protection" and "Principle of 2-2 rules".

\section{a) Principle of moving to higher ground}

The east coast of the Tohoku region has suffered from tsunamis again and again in their history. Some villages were moved to higher ground after a historical tsunami attack. After the move, some villages stayed on higher ground; almost all of them were safe from the 2011 tsunami. Other villages, however, expanded to lower ground again for usability with population growth; the lower ground was devastated by the tsunami in 2011 .

Before the decision of the new standard for the tsunami protection level, the national and municipal governments proposed a "principle of moving to higher ground" for the reconstruction plan, based on the history of the region. This is quite a natural thing.

This principle was introduced mainly at the ria coast, in the northern part of the east coast of Tohoku region.

\section{b) Principle of multi-layer protection}

On the Sendai Plain, the high bank of the East Sendai Expressway stopped the tsunami, just like an inland levee. Inspired by this experience, reconstruction planners proposed the principle of multi-layer protection as a new concept against the huge scale of the tsunami. A coastal levee will protect against L1 and reduce the energy of L2, and L2 will be stopped by a high-banked road or railway as an inland levee, with residential land use being prohibited between coastal levee and inland levee.

This principle is introduced only at the sandy coast in the plains area, the southern part of the east coast of Tohoku region, because the plains area has no hills and mountains for moving to higher ground.

\section{c) Principle of 2-2 rules}

The coastal levee only protects against L1, thus L2 will certainly inundate the area. To reduce the damage from L2, it is important to consider the 
damage tolerance level.

Koshimura et al. (2009) ${ }^{10)}$ and Suppasri et al. $(2012)^{11)}$ analyzed fragility functions for tsunami damage from empirical data. The results of both show that $2 \mathrm{~m}$ of inundation depth and $2 \mathrm{~m} / \mathrm{s}$ of current velocity is the critical value, because the damage probability jumps up from a depth of $2 \mathrm{~m}$ and a velocity of $2 \mathrm{~m} / \mathrm{s}$.

Many tsunami-affected municipal governments use these researches as a basis of land use planning. They prohibit residential land use where the result of L2 tsunami simulation shows an inundation depth of over $2 \mathrm{~m}$ and current velocity of over $2 \mathrm{~m} / \mathrm{s}$. This is called the " $2-2$ rules". In other words, they set the 2-2 rules as the damage tolerance level of residential land use, which tolerates an inundation but avoids a washing out by L2. On the other hand, projects for raising the ground level are also planned to enlarge areas for residential use. The height of the mound up is designed according to the 2-2 rules through the L2 simulation.

\section{DILEMMAS AND DIFFICULTIES IN RECONSTRUCTION PLANNING}

Reconstruction planning of a city/town/village is set as the principal task of the municipal government without delegation of authority for administration. In fact, they are not administrators of major infrastructures. For example, almost all trunk roads are prefectural roads or national roads. The administrators of river and coastal levees are the same. Therefore, the municipal government struggles to coordinate several reconstruction plans for major infrastructures.

Moreover, sectionalism forces a planner to coordinate different sections. For example, there are five types of coastal administration in Japan. Each type of coast is administered by a different law, which is under a different ministry, bureau, or agency. Thus, the design standard, budget system, and planning and construction progress are different for each of the five types.

Therefore, the process of reconstruction planning is a struggle of coordination.

The actual post-tsunami reconstruction plan of municipal governments is now being investigated with regard to the comprehensive problem, introduced in section 2 , and the tsunami specific principle, introduced in the last chapter.

Based on those above discussions, dilemmas and difficulties in the actual reconstruction plan are introduced in this section.

It is possible to classify roughly the actual reconstruction plan into two types. One is the ria coast type, and the other is the plains type. Generally, the wavelength of a tsunami is very long. It is said that the wavelength of a tsunami is from several kilometers to several hundred kilometers. Thus, a tsunami has the character not of a wave but a flow. Therefore, a tsunami, as a flow, on the ria coast is terribly concentrated to the end of a bay by steep geographical conditions. Thus the height, and also the velocity, of the tsunami will become very high on the ria coast. On the other hand, along the sandy shore on the edge of a plain, the power of the tsunami is comparatively weak, but there is no hill to run to and avoid it.

\section{(1) Reconstruction plan for ria coast}

\section{a) Dilemma of compact city/town/village on ria coast}

The main issue of the reconstruction planning on the ria coast is moving to higher ground. The project of moving to higher ground has many problems, though it is an important principle.

The first problem of moving to higher ground is a project under population decline, which is very severe in rural areas in Japan. No one will be able to clearly explain how many people will live in the newly developed higher ground after 30 years and how many people will move in as the next generation. Many have expressed the pessimistic opinion that no one would be living on the new higher ground after 30 years. Therefore, it seems that the huge cost of developing it is not appreciate public investment. No one checked the projects by cost benefit analysis. It is possible to say that safety has strong priority in this reconstruction planning, even if it is not reasonable.

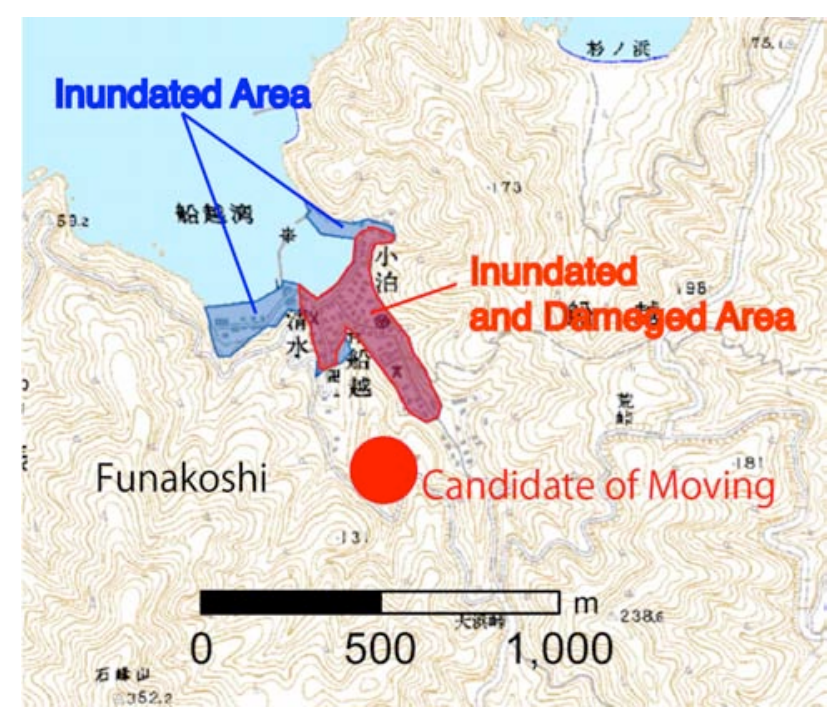

Fig. 3 Inundated area and candidates for moving to higher ground in Funakoshi, Ishinomaki, Miyagi Prefecture. (copyright at Geospatial Information Authority of Japan and Miyagi prefectural Government. Candidate for Moving to higher ground is added by Author.) 
The second problem is the concept of a compact city/town/village. In fact, the surrounding mountains of the city/town/village are very steep, thus, almost all candidates of the move to higher ground are apart from the fishing port, the case of Funakoshi village in Ishinomaki is shown in Fig. 3, for example. In the case of Funakoshi in Ishinomaki, the access road to higher ground is a detour, because of the steep slope. This is directly contrary to the concept of a compact city. The residences are located in the mountains and the workplace, such as a fish-processing factory, is located behind the fishing port. Almost all new cities/towns/villages will be separated ones. In some reconstruction plans, the commercial area is also located in an old town near the fishing port without residences around shops. This separated form of the city/town/village will surely accelerate population decline.

The third problem is related to the goal of the reconstruction plan. The tsunami washed out the historically cultivated rural landscape. It is a severe break in the regional tradition of the landscape. However, several things remain. Streets, views from streets, a shrine on the hillside, and the composition or relation of facility and nature (Fig. 4). The project of moving to higher ground will mean abandoning the old traditional lower ground except for industrial areas and fishing ports. It means that local property or landscapes will be abandoned intentionally. Without traditional and historical places or landscapes, it will be hard to reach the goal of the reconstruction plan, which are greater place attachment and more pride for one's own town. In post-modern planning, it seems common sense that it will take a long time to develop a place attachment in a brand-new town.

To mitigate these problems, several cities and towns, such as the city of Rikuzen Takada and the

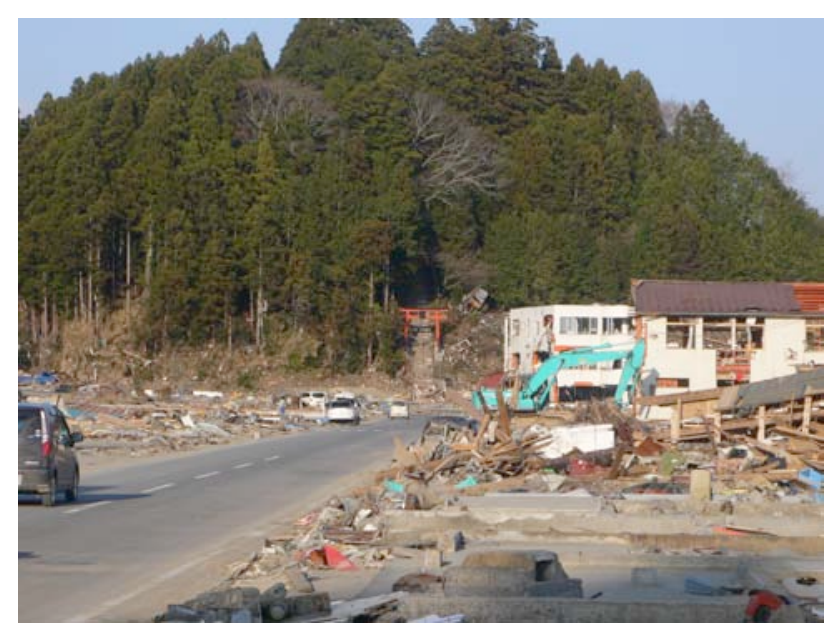

Fig. 4 Remaining traditional composition of Shrine and high street in Utatsu, Minami-Sanriku, Miyagi Prefecture. town of Ohtsuchi, have introduced raising the ground level of the old lower city/town centre using the $2-2$ rules.

Unfortunately, this mitigation method has been applied only at Iwate Prefecture. This is because the "frequently occurring tsunami" of Iwate Prefecture, which is located in the northern part of the ria coast, is quite high (from $10 \mathrm{~m}$ to $15 \mathrm{~m}$ )-the Meiji Sanriku Tsunami (1896), Showa Sanriku Tsunami (1933) and Chile Earthquake Tsunami (1960) were all high at the Pacific coast of Iwate Prefecture. Thus, the designed height for L1 became higher than for the standard L1. Therefore, in Iwate Prefecture, the L1 levee will be able to reduce L2 energy sufficiently. Because of that, raising the ground has become a possible alternative in Iwate Prefecture.

On the other hand, in the southern part of the ria coast, which is in Miyagi Prefecture, those frequently occurring historical tsunamis were comparatively low, fortunately. Thus the designed height for L1 is also low. Therefore, based on the 2-2 rules, the project of raising the ground level is an impractical plan in the southern part of the ria coast. The raising of the ground level is used only for recovering from subsidence, which occurred because of the earthquake, to keep a natural drainage. Also, residential land use is prohibited by land use control, under the 2-2 rules.

\section{b) Dilemma of L1 levee and land use of lower ground}

After moving to higher ground, many vacant lands will appear on lower ground, though the latter will be protected by an L1 levee. Related to the L1 levee and land use of lower ground, there are also several problems.

The first problem is related to land use control. Municipal governments will prohibit residential land use in lower land inundated by the tsunami to avoid future tragedy. However, this restriction includes some doubt. There are numerous probable flood areas along a river in Japan. As mentioned in the last section, in terms of river flooding, the protection level is only from 30-years flood to 200-years flood even in the case of major rivers, which is directly controlled by the national government. Probable flood areas are shown in river flood hazard maps and open to the public, but there are no restrictions for land use. Considering the frequency of L2, it seems that to prohibit residential land use against L2 shows lack of coordination with planning for river flood, because there will be protection against L1. On the other hand, considering L2's power to devastate, it seems reasonable though it will occur only once per 500 years. 
The second problem is related to land use itself. After moving to higher ground, large tracts of vacant land will appear on lower ground. There are no suitable land uses for the vacant land. In the reconstruction plan of some municipal governments, large memorial parks are planned for vacant lower ground. Concerning the maintenance cost of a large park, it has a high probability of becoming an impracticable plan. In another lower area, agricultural land use is being planned. This idea is quite natural, in fact, in a past move to higher ground, land use was changed from residential to agricultural. However, in terms of agriculture, the vacant lower ground is not large enough for modern, efficient large-scale agriculture. Moreover, it costs much to remove all the base of the houses and to cover the ground with good topsoil for farming.

The third problem is related to the $\mathrm{L} 1$ levee itself. In case of a small fishing village, only some fishing facilities will remain at lower ground after moving to higher ground. An L1 levee is planned even in such a case, because to protect from L1 is a national decision just like national minimum. Needless to say, the construction plan for the L1 levee should be coordinated with the plan of moving to higher ground and so on, but the coordination is not sufficient, because of sectionalism. At least, some standard for the construction of the L1 levee is required, otherwise a high coastal embankment will appear with nothing to protect. Moreover, a high L1 levee is just an obstacle to the daily life of a fisherman. It will reduce accessibility to fishing ports, and it will hide the view of the sea, which is very important not only for practical information for fishing but also the local cultivated landscape. The L1 levee is high enough to break the visual, cultural and traditional relationship between sea and village. In fact, the height of the $\mathrm{L} 1$ levee is from $5.0 \mathrm{~m}$ to $15.5 \mathrm{~m}$ in the ria coast area. To mitigate the visual impact of the coastal levee, the Ministry of Land Infrastructure and Transportation made a guidance document for building coastal embankments with landscaping and visual quality design ${ }^{12)}$ as a national authority of a levee. The guidance includes a horizontal alignment method to set a levee into the surrounding landscape naturally and a design method for visual qualities using gestalt psychology. The guidance was made with support from the Landscape and Civic Design Committee of the JSCE. However, the height of the levee is more critical than the visual quality design. Even if actual design of levee has done with these mitigation methods, the height will be rule whole landscape. Therefore, actual construction height of the coastal embankment should be considered with these viewpoints, separately from the design height.

\section{c) Summary of the dilemma on the reconstruc- tion plan of ria coast type}

Through the above discussion, giving up the move to higher ground seems one of the solutions for several dilemmas. If the city/town/village would be reconstructed on lower ground the same as before with the full height of the L1 levee, it will surely become a compact city/town/village and it will certainly be the shortest path to the goal. However, this clear and rational alternative has not been taken, because of the "once per 500 years vs. actually experienced" tsunami. The sense of time is essential and a crucial point for reconstruction planning.

\section{(2) Plains-type reconstruction plan \\ a) Dilemma of multi-layer protection}

To mitigate the gap in the sense of time, the principle of multi-layer protection is taken at the reconstruction plan for plains-type areas. The representative project of multi-layer protection is a second levee and land use control based on two levees as mentioned in section 4. The concept of a second levee was proposed immediately after the tsunami, but in fact, there is no suitable project scheme for a second levee in Japan. The high-banked road that stopped the tsunami is a motorway. It was designed as a high bank just to pass over a local road. Without such clear reasons, it is naturally impossible to construct a high-banked road within the project scheme in Japan. The project scheme of a second levee was established in the new act for regional development with tsunami countermeasure at the end of 2011. However, this act and related ordinances require severe conditions to construct a second levee, because the frequency of L2 is quite rare. In fact, a second levee over $500 \mathrm{~m}$ will not be subsidized by the national government. Considering the financial situation of the municipal government, this is virtual rejection for the construction of a second levee, although almost all municipal governments along the sand coast had a plan for a second levee. In the end, all municipal governments changed the strategy to construct a high-banked road as a second levee. They went back on the road project scheme for a high-banked road because of the 'clear reason' of an evacuation route. This confusion was also caused by the gap in sense of time.

\section{b) Dilemma of compact city/town in plains-type areas}

In the case of a plains-type reconstruction plan, a dilemma of the compact city/town appears from different point compared with the ria-type plan. Municipal governments along the sand coast prohibit residential land use between the coastal levee and the second levee, as mentioned in the last section. All residents who lived in the outer area of the 
second levee will move into a more inland area or behind a second levee except some reconstruction plans. In contrast to the ria-type plan, the direction of the move is coordinated with the concept of a compact city/town, because the city/town centre is located in the inland area.

Actually, there are many vacant lands in and around the city centre located in inland areas, but the vacant land will not be able to be a candidate for moving destinations, though all lifeline is ready to live. The real estate transaction problem, mentioned in section 2, blocks the fastest and the most ideal way to reconstruction. As a result, large new developments are required, which involves spending a long time and a large cost, even in the population decline phase. This is the most severe dilemma in the plains-type reconstruction plan.

If the people succeed in moving into vacant land in and around the city/town centre, another problem will still remain. Moving inland also means breaking with the cultivated local landscape, the same as moving to higher ground at the ria coast. The previous small village in the Sendai Plain has a rich cultivated landscape. It is called "igune". The small village is located by a natural levee, and the windbreak trees surround a house and village. The damage from the tsunami is comparatively small at the "igune" (Fig. 5). This kind of cultural landscape should be inherited by the future generation.

Moreover, land price is a troublesome matter. The value of land along the coast is low compared with the inland area, because the city/town centre is located inland. When tsunami survivors who lived out of a second levee are forced to move residence inland by regulations, they will be able to sell their former land to the public, but they should buy or rent new land from the public sector by themselves. The case of rent is not so big a problem, because the rent will be free for 30 years due to a subsidy. However, in the case of buying, the tsunami survivor will hesitate to move, faced with the difference in land price. In fact, a small resistance against moving occurred in the coastal area of Sendai last year.

Fortunately, the previous land use of inundated areas is agricultural except in a small coastal village in the plains area. In fact, several reconstruction plans for the plains include large memorial parks as in the ria coast, but it is not the majority. Thus, the land use problem of former residential land is not so big in contrast with the ria coast-type plan. Of course, the land inundated by salty seawater will not produce agricultural products immediately, and the cost of recovery is not cheap. It might be hard to recover, but this option is more hopeful compared with the low ground of the ria coast.

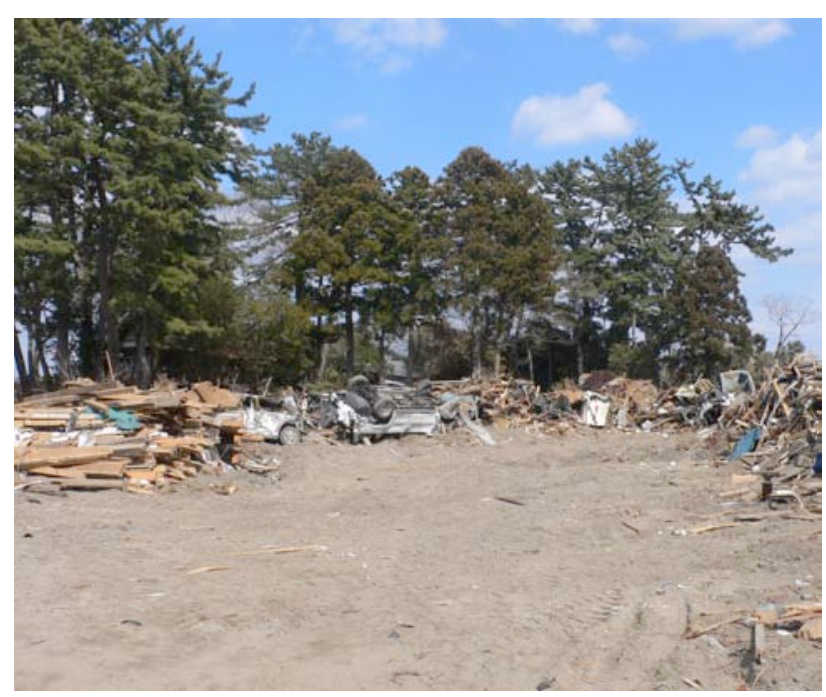

Fig. 5 Remaining traditional "igune" in Natori, Miyagi Prefecture.

\section{c) Summary of the dilemma in the plains-type reconstruction plan}

Generally, the dilemma in the plains-type plan does not seem so severe compared with the ria coast plan, but this just means that the dilemma of the ria coast is terribly serious. Anyway, the move to higher ground or an inland site means directly abandoning the old traditional cultivated city/town/village. This might be a critical break for both the local cultivated landscape and the real goal of reconstruction. This essential problem is common between the ria coast and the plains.

\section{CONCLUDING REMARKS}

The time limitation of the reconstruction project is just five years based on its budget and reconstruction scheme. It will end in the fiscal year of 2015 . Until the deadline, the enormous actual plan and design should be finished for faster recovery. All reconstruction projects are faced with shortages in planners, designers, project managers and construction material. It will be easy to proceed with the reconstruction project without considering the dilemmas discussed, but the quality of the reconstruction project will decide not only the tsunami survivor's quality of daily life, but also the future of the region itself. All projects will have a strong influence on the tsunami-affected region during their project life (50-100 years long).

All planners, designers, project managers and public officers should struggle to address those dilemmas for the future of the region, even if they will not find a good solution. 
ACKNOWLEDGMENTS: The essence of this article is based on an enormous number of discussions with colleagues, planners, public officers and the tsunami survivors. Deep appreciation is expressed to them. Professor Yasuaki ONODA, Associate Professor Michio UBAURA and Assistant Professor Kentarou IMAI are especially appreciated for being not only the author's colleagues at Tohoku University, but also his co-workers at the City of Ishinomaki. Moreover, the Editorial Committee of the Journal of JSCE is appreciated for granting this great opportunity to the author.

\section{REFFERENCES}

1) Cabinet Office, Government of Japan: White Paper on Disaster Management 2011 Executive Summary (Provisional Translation), 2011.

http://www.bousai.go.jp/hakusho/WPDM2011_Summary.pdf

More detailed information on the tsunami damage is available in the White Paper on Disaster Management 2012 (in Japanese).

2) National Institute of Population and Social Security Research, Japan: Population Projection for Japan 2012, 2012 (in Japanese). English version is available only in 2006, The Japanese Journal of Population, Vol. 6, No.1, pp. 76-114, 2008.

http://www.ipss.go.jp/webj-ad/WebJournal.files/population /2008_4/05population.pdf

3) Town of Minamisanriku: Draft plan of reconstruction version of 18 Sep 2011, 2011 (in Japanese). http://www.town.minamisanriku.miyagi.jp/uploads/ftp_co mmon/sakuteikaigi/20110918soan.pdf

4) City of Ishinomaki: Central City Area Activation Basic Plan of Ishinomaki 2009 (in Japanese).

http://www.city.ishinomaki.lg.jp/shokokanko/shigaichi/kih onplan_pdf.jsp

5) City of Ishinomaki: Comprehensive Plan of Ishinomaki 2007 (in Japanese).

http://www.city.ishinomaki.lg.jp/sougouseisaku/plans/soug oukeikaku2007.jsp
6) Kennedy, J., Ashmore, J., Babister, E. and Kelman, I. : The Meaning of Build Back Better: Evidence from Post-Tsunami Aceh and Sri Lanka, Journal of Contingencies and Crisis Management, Vol. 16, Issue 1, pp. 24-36, 2008.

7) Ministry of Finance, Government of Japan: Japanese Fiscal condition date, 2011 (in Japanese).

English version available, 2010

http://www.mof.go.jp/english/budget/statistics/201006/ind ex.html

8) Committee for Technical Investigation on Countermeasures for Earthquakes and Tsunamis Based on the Lessons Learned from the "2011 off the Pacific coast of Tohoku Earthquake", Central Disaster Prevention Council: Interim Report of the Committee for Technical Investigation on Countermeasures for Earthquakes and Tsunamis Based on the Lessons Learned from the "2011 off the Pacific coast of Tohoku Earthquake", 2011.

An English version of the abstract of the final report is available at

http://www.bousai.go.jp/jishin/chubou/higashinihon/Report.pdf

9) Sugawara, D., Imamura, F., Goto, K., Matsumoto, H. and Minoura, K.: The 2011 Tohoku-oki Earthquake Tsunami: Similarities and Differences to the 869 Jogan Tsunami on the Sendai Plain, Journal of Pure and Applied Geophysics, Published online, 2012.

DOI: 10.1007/s00024-012-0460-1, 2012.

10) Koshimura, S., Oie, T., Yanagisawa, H. and Imamura, F. : Developing Fragility Functions For Tsunami Damage Estimation Using Numerical Model And Post-Tsunami Data From Banda Aceh, Indonesia, Coastal Engineering Journal, Vol.51, No.3, pp. 243-273, 2009.

11) Suppasri, A., Mas, E., Koshimura, S., Imai, K., Harada, K. and Imamura, F. : Developing Tsunami Fragility Curves From The Surveyed Data Of The 2011 Great East Japan Tsunami In Sendai And Ishinomaki Plains, Coastal Engineering Journal, Vol. 54, No. 1, 1250008 (16 pages), 2012.

12) MILT, Design Guidance to Mitigate the Visual Impact of the Embankment. 2011 (in Japanese).

http://www.mlit.go.jp/river/shinngikai_blog/hukkyuukeikan/

(Received August 13, 2012) 